\title{
Diabetes therapy by lentiviral hepatic insulin gene expression without transformation of liver. Reply to Elsner M, Jörns A, Lenzen S [letter]
}

\author{
A. M. Simpson • B. A. O'Brien
}

Received: 15 January 2008 / Accepted: 18 January 2008 / Published online: 5 February 2008

(C) Springer-Verlag 2008

To the Editor: We would like to thank Dr Elsner and colleagues for the interest they have shown in our work [1, 2]. To comment properly on the data, however, we would have to see more details of their study regarding the longevity of blood glucose reduction and the results of glucose tolerance tests. We think that without this additional information it is difficult to comment on the efficacy of their procedure and the claims that transdifferentiation is not required. We think it is logical to predict normalisation of glucose levels after hepatic expression of insulin, and this has been shown to a greater or lesser extent in numerous studies. In Elsner's study it is not clear whether this reduction in blood glucose levels can be sustained without induction of hypoglycaemia and whether glucose secretion was tightly regulated. Indeed the blood glucose level of the animals was not reduced to anywhere near normal levels. Whilst insulin staining was seen, there are no data to show whether or not this was in secretory granules, as was seen in our study. While there has been some indication that the type of furin-cleavable insulin used in this study may cause mutations, the transdifferentiation seen in our study is not a sole result of this, if at all. In previous preliminary work we have delivered this insulin in different vectors and by different methods, and seen no transdifferentiation or such tightly controlled blood glucose homeostasis as seen in the study published in Diabetologia. We wait with interest to see Dr. Elsner's data once they are published.

\section{References}

1. Elsner M, Jörns A, Lenzen S (2008) Diabetes therapy by lentiviral hepatic insulin gene expression without transformation of liver. Diabetologia DOI 10.1007/s00125-008-0931-1

2. Ren B, O'Brien BA, Swan MA et al (2007) Long-term correction of diabetes in rats after lentiviral hepatic insulin gene therapy. Diabetologia 50:1910-1920
A. M. Simpson $(\bowtie) \cdot$ B. A. O’Brien

Department of Medical \& Molecular Biosciences, University of Technology Sydney,

P.O. Box 123 Broadway, NSW 2007, Sydney, Australia

e-mail: Ann.Simpson@uts.edu.au 